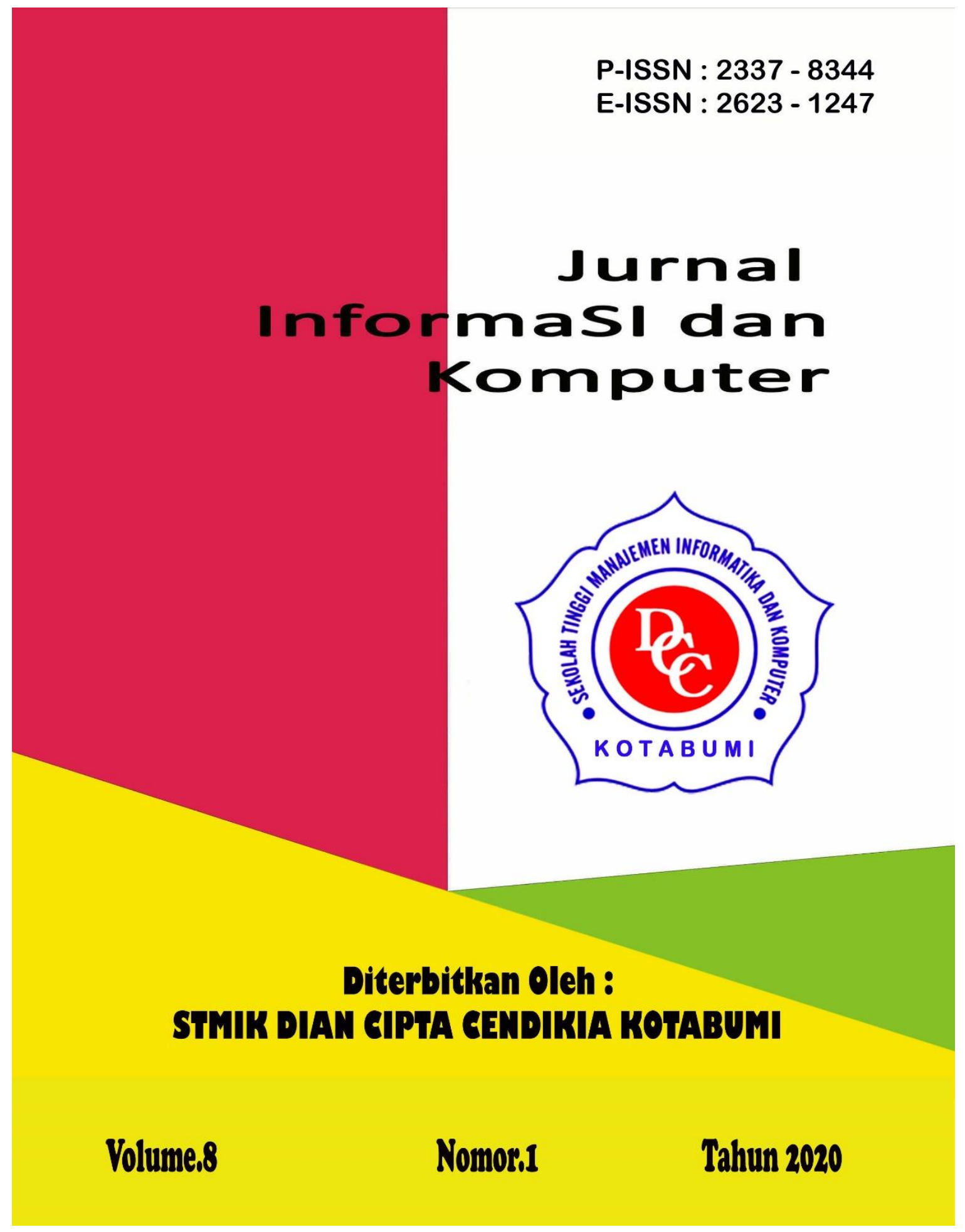


Penerbit:

STMIK DIAN CIPTA CENDIKIA KOTABUMI

Bekerjasama dengan LPPM STMIK DCC Kotabumi

Hak atas naskah/tulisan tetap berada pada penulis, isi diluar tanggung jawab

Penerbit dan Dewan Penyunting

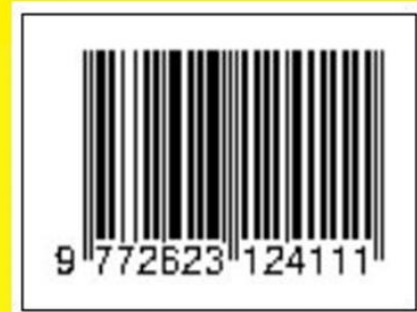




\section{PENGANTAR REDAKSI}

Puji syukur dipanjatkan kehadirat Tuhan Yang Maha Esa, atas karunia dan limpahan rahmatNYA jualah Jurnal Informatika dan komputer (InfoKom) STMIK Dian Cipta Cendikia Kotabumi ini dapat terwujud.Jurnal Informatika dan Komputer (InfoKom) yang terbit dua (2) kali dalam setahun ini merupakan suatu wadah untuk penyebar luasan hasil-hasil penelitian, studi pustaka, karya ilmiah yangberkaitan dengan Informatika dan Komputer khususnya bagi dosen-dosen STMIK Dian Cipta Cendikia Kotabumi serta umumnya para cendikiawan, praktisi, peneliti ilmu Informatika dan Komputer.

Harapan, dengan diterbitkannya Jurnal Informatika dan Komputer (InfoKom) ini sebagai salah satu bentuk sumbangan pemikiran dalam pengembangan ilmu informatika dan komputer yang berkaitan dengan kajian-kajian di bidang tekhnologi Informatik, Komunikasi Data dan Jaringan Komputer, perancangan dan Rekayasa Perangkat Lunak, serta ilmu-ilmu yang terkait dengan bidang Informatika dan Komputer lainnya.

Berkenaan dengan harapan tersebut, kepada para peneliti, dosen dan praktisi yang memiliki hasil-hasil penelitian, kajian pustaka, karya ilmiah dalam bidang tersebut diatas, dengan bangga redaksi Jurnal Informatika dan Komputer (JIK) menerima naskah ringkasan untuk dimuat pada jurnal Informatika dan Komputer (InfoKom) STMIK Dian Cipta Cendikia Kotabumi dengan berpedoman pada penulisan naskah jurnal sebagaimana dilampirkan pada halaman belakang (Bagian kulit dalam) buku jurnal ini.

Mutu dari suatu jurnal ilmiah tidak hanya ditentukan oleh para pengelolanya saja, tetapi para penulis dan pembaca jualah yang mempunyai peranan besar dalam meningkatkan mutu jurnal Informatika dan Komputer ini. Merujuk pada realita ini kamu sangat mengharapkan peran aktif dari peneliti untuk bersama-sama menjaga dan memelihara keberlangsungan dari jurnal Informatika dan Komputer STMIK Dian Cipta Cendikia Kotabumi ini. Yang juga tidak kalah pentingnya dari partisipasi tersebut diatas, adalah saran dan kritik yang membangun dari pembaca yang budiman agar kiranya dapat disampaikan langsung kepada redaksi JIK. Saran dan kritik yang membangun akan dijadikan masukan dan pertimbangan yang sangat berarti guna peningkatan mutu dan kualitas Jurnal Informatika dan Komputer STMIK Dian Cipta Cendikia Kotabumi.

Tak lupa diucapkan terima kasih yang tak terhingga atas perhatian dan kerjasama dari semua pihak yang tak dapat disebutkan satu persatu hingga dapat diterbitkan nya Jurnal Informatika dan Komputer (InfoKom) STMIK Dian Cipta Cendikia Kotabumi. Semoga apa yang telah diperbuat untuk kebaikan akan menjadi amal ibadah, amin.

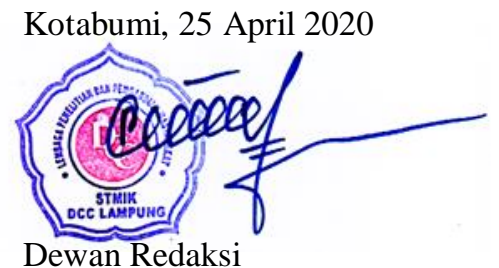




\section{JURNAL INFORMASI DAN KOMPUTER}

Volume 8 Nomor 1 April 2020

Jurnal Informasi dan Komputer merupakan Sarana informasi ilmu pengetahuan, Tekhnologi dan Komunikasi yang berupa hasil penelitian, tulisan ilmiah, Ataupun studi pustaka. Jurnal ini terbit dua kali setahun pada bulan April dan Oktober. Berisi hasil penelitian ilmiah di bidang informatika yang bertujuan untuk menghubungkan adanya kesenjangan antar kemajuan teknologi dan hasil penelitian. Jurnal ini di terbitkan pertama kali pada tahun 2013.

Penanggung Jawab:

Ketua STMIK Dian Cipta Cendikia

Kotabumi

\section{Pembina:}

Ketua STMIK Dian Cipta Cendikia

Kotabumi

Ketua Lembaga Penelitian STMIK Dian

Cipta Cendikia Kotabumi

\section{Pimpinan Redaksi}

Dwi Marisa Efendi,.S.Kom.,M.Ti

\section{Redaksi pelaksana}

Rustam,.S.Kom,.M.Ti (STMIK Dian

Cipta Cendikia Kotabumi)

Nurmayanti M.Kom (STMIK Dian

Cipta Cendikia Kotabumi)

Sukatmi,.S.Kom., M.Kom (AMIK DCC

Bandar Lampung)

Sampurna Dadi Riskiono,M.Kom

(Universitas Teknokrat Indonesia)

Ifo Wahyu

Pratama,S.Kom.,M.Ti(AMIK MASTER

Lampung)

\section{Mitra Bestari}

Merri Parida.,M.Kom (STMIK Dian

Cipta Cendikia Kotabumi)

Amarudin,S.Kom.,M.Eng (Universitas

Teknokrat Indonesia)

Didi Susianto.,S.T.,M.Kom (AMIK

DCC Bandar Lampung)

Alhibarsyah.,S.T.,M.Kom (Stmik Tunas

Bangsa Bandar Lampung)

Kemal Farouq Mauladi

.,S.Kom.,M.Kom (Universitas Islam

Lamongan)

Agus Setiawan S.Pd.,M.Eng

(Universitas Muhammadiyah

Lamongan)

Penerbit : STMIK Dian Cipta Cendikia Kotabumi Bekerja Sama Dengan LPPM STMIK Dian Cipta Cendikia Kotabumi.

\section{Alamat Redaksi/Penerbit:}

Jl. Negara No. 3 Candimas Kotabumi

Lampung Utara

No Telpon/Fax 072423003

Email : 1ppm-stmik@dcc.ac.id 


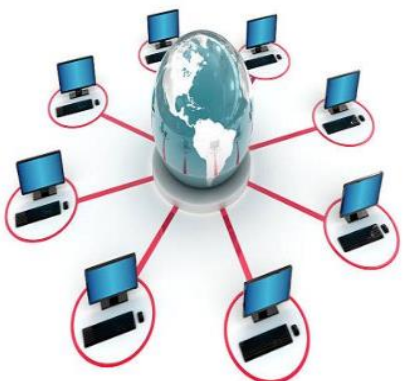 \\ JURNAL INFORMASI DAN KOMPUTER VOL. 8 NO. 1 THN. 2020}

\section{DAFTAR ISI}

\section{Halaman}

Sistem Pendukung Keputusan Penentuan Lahan Kopi Terbaik Dengan Metode Ahp (Analytic Hierarchy Process)

Sidik Rahmatullah, Rendy Abdurahman (AMIKKOM Jogja, STMIK Dian Cipta Cendikia Kotabumi)

Rancang Bangun Sistem Informasi Pada Program Pembangunan Pemberdayaan Masyarakat Desa( P3md ) Berbasis Web Mobile Ferly Ardhy, Firmansyah, Sidik Rahmatullah,(IIB Darma Jaya Bandar Lampung STMIK Dian Cipta Cendikia Kotabumi, AMIKKOM Jogja) 08-12

Sistem Informasi Pengolahan Data Alumni Sekolah Menengah Atas (Sma)

Merri Parida, Nindiya Ova Rahmawati (AMIKKOM Jogja,

STMIK Dian Cipta Cendikia Kotabumi)

SISTEM INFORMASI GEOGRAFIS PUSKESMAS BESERTA SARANA

DAN PRASARANA BERBASIS WEB MOBILE

Nurmayanti, Windy Dwi Bahari (AMIKOM Jogja,

STMIK Dian Cipta Cendikia Kotabumi)

Rancang Bangun Sistem Informasi Konseling Untuk Sekolah Menengah Kejuruan

(Smk) Berbasis Website

Aliy Hafiz1, Galih Rakasiwi, Ifo Wahyu Pratama, Agus Komarudin,

Bambang Suparapto, Fathurrahman Kurniawan Ikhsan

(AMIK Dian Cipta Cendikia Bandar Lampung,

Universitas Nahdhatul Ulama Lampung, AMIK Dian Cipta Cendikia Pringsewu,

Universitas Mitra Indonesia, Lampung) .....

Sistem Pendukung Keputusan Pemilihan Driver Terbaik Menggunakan Metode

Weight Product (Wp)

Dina Lorenza, Pitrawati (STMIK Dian Cipta Cendikia Kotabumi

AMIK Dian Cipta Cendikia)

Rancang Bangun Sistem Informasi Pembayaran Mahasiswa

Darsin(Universitas Megou pak Tulang Bawang)

Sistem Informasi Geografis Bengkel Motor Honda Resmi Bandar Lampung

Sukatmi, Nuraini (AMIK Dian Cipta Cendikia Bandar Lampung).....

Sistem Pakar Diagnosa Penyakit Kulit Wajah Dengan Metode

Certainty Factor Pada Klinik Skin Rachel

Dwi Marisa Efendi, Putri Yulita Sari (IIB Darmajaya Bandar Lampung,

STMIK Dian Cipta Cendikia Kotabumi)..... 
Sistem Informasi Monitoring Siswa Pada Mts Al-Islamiah Bunut Kabupaten Pesawaran Yuli Syafitri ${ }^{2}$, Reni Astika ${ }^{1}$, Septian Hernando $^{3}$ AMIK Dian Cipta Cendikia

Aplikasi Kamus Bahasa Jepang Berbasis Mobile Android

Rustam $^{2}$, A Yanda Febry Pangestu ${ }^{2}$ Sistem Informasi, Teknologi Komputer ${ }^{1}$, IIB Darmajaya

Bandar Lampung ${ }^{2}$ STMIK Dian Cipta Cendikia Kotabumi 


\title{
RANCANG BANGUN SISTEM INFORMASI PADA PROGRAM PEMBANGUNAN PEMBERDAYAAN MASYARAKAT DESA ( P3MD ) BERBASIS WEB MOBILE
}

\author{
Ferly Ardhy ${ }^{1}$, Sidik Rahmatullah ${ }^{2}$, Firmansyah $^{3}$ \\ Sistem Informasi ${ }^{1}$, Teknologi Komputer ${ }^{2}$, Sistem Informasi ${ }^{3}$ \\ ${ }^{1,2,3}$ STMIK Dian Cipta Cendikia Kotabumi \\ Jalan Negara No 03 Candimas Kotabumi Lampung Utara \\ E-mail : ferly@dcc.ac.id ${ }^{1}$, $\underline{\text { sidik@ @cc.ac.id }}^{2}$, syah8646@ gmail.com $^{3}$
}

\begin{abstract}
ABSTRAK
Program Pembangunan Pemberdayaan Masyarakat Desa ( P3MD ) Lampung Utara merupakan sebuah lembaga yang bergerak dalam bidang Pemberdayaan Masyarakat Desa. Program Pembangunan Pemberdayaan Masyarakat Desa Lampung Utara memerlukan sebuah media alternatif untuk dapat berbagi informasi yang bersifat pembangunan maupun non pembangunan, khususnya bagi P3MD. Dan memerlukan media penyebarluasan informasi ke publik atau masyarakat luas, agar lebih memudahkan dalam mendapatkan informasi tersebut bagi pihak-pihak yang membutuhkan.

Adapun pengembangan yang digunakan dalam penelitian ini adalah pengembangan dengan model Object Oriented yang menggunakan beberapa alat bantu seperti Use Case dan Diagram Activity,. Dan untuk metode pengembangan sistem yang digunakan adalah metode Extreme Programming (XP). Metode pengembangan Extreme Programming $(X P)$ merupakan urutan aktivitas yang dimulai dari pengumpulan kebutuhan, membangun Extreme Programming $(X P)$, evaluasi Extreme Programming $(X P)$, mengkodekan sistem, menguji sistem, evaluasi sistem, dan menggunakan sistem.
\end{abstract}

Dengan diterapkannya Sistem Informasi Program Pembangunan Pemberdayaan Masyarakat Desa ( P3MD ) Lampung Utara Berbasis WEB Mobeli, memungkinkan masyarakat luas akan merasa terbantu dalam memperoleh informasi seputar P3MD maupun seputar pembangunan. Sistem Informasi P3MD juga dapat meningkatkan kinerja, kualitas pelayanan, dan juga daya saing .

Kata kunci: Sistem Informasi, Sublime Text, Web Mobile.

\begin{abstract}
The North Lampung Village Community Empowerment Development Program (P3MD) is an institution engaged in the field of Village Community Empowerment. The North Lampung Village Community Empowerment Development Program requires an alternative media to be able to share development and non-development information, especially for P3MD. And requires the media dissemination of information to the public or the wider community, so it is easier to get the information for those who need it.
\end{abstract}

The development used in this research is the development of the Object Oriented model which uses several tools such as Use Case and Activity Diagram. And for the system development method used is the Extreme Programming (XP) method. The Extreme Programming (XP) development method is a sequence of activities that start from gathering needs, building Extreme Programming (XP), evaluating Extreme Programming $(X P)$, coding the system, testing the system, evaluating the system, and using the system.

With the implementation of the North Lampung Community Empowerment Village (P3MD) Development Program Information System based on WEB Mobeli, it allows the wider community to feel helped in obtaining information about P3MD and about development. P3MD Information Systems can also improve performance, service quality, and competitiveness. 
Keywords: Information Systems, Sublime Text, Mobile Web.

\section{PENDAhuluan}

Pembangunan pedesaan dewasa ini mengalami perubahan signifikan baik dalam segi konsep maupun prosesnya.Konsep pembangunan tidak lagi sebatas pada sektor agraris dan infrastruktur dasar tapi mengarah pada pengembangan Teknologi Informasi dan Komunikasi (TIK). Proses pembangunan pedesaan kemudian semakin mengurangi ketergantungan pada peran pemerintah, sebab masyarakat pedesaan semakin berdaya dan kreatif dalam mengembangkan inovasi.

Pembangunan masyarakat dan pengembangan wilayah pedesaan melibatkan berbagai faktorfaktor sosial, ekonomi, budaya dan teknologi, yang satu sama lain saling berinteraksi dalam proses pembangunan. Setiap pembangunan menawarkan perubahan, yang dampaknya terhadap satu wilayah dengan wilayah lainnya boleh jadi akan berlainan, karena karateristik suatu wilayah dengan wilayah lain berlainan.Pelaksanaan pembangunan pedesaan di era digital ini memerlukan sistem komunikasi konvergen melibatkan komunikasi interpersonal, media massa dan media hibrida (istilah lain untuk internet). Tujuannya agar banyak pihak dari berbagai generasi dapat terlibat dan berpartisipasi untuk mempercepat tujuan pembangunan.Sebab proses pembangunan tidak bisa mengabaikan keterlibatan berbagai elemen masyarakat.

Salah satu program yang ada di desa adalah Program Pembangunan Pemberdayaan Masyarakat Desa ( P3MD ) program ini yang bergerak dibidang Pengawasn, yaitu Pengawasan Pembangunan dan Pengunanan Anggaran Dana Desa. Dalam hal penyamapaian hasil dari pengawasan yang sudah dilakukan masih kurang maksimal, kurangnya musyawarah dalam penyusunan programprogram desa, tidak koordinasi dalam pelaksanaan program-program desa, dan peningkatan kualitas kinerja di pemerintahan desa dan informasi tentang program yang ada di kementerian desa belum maksimal sampai di masyarakat. Maka dari itu dibutuhkan sebutah teknologi berupa websiteyang berbasis mobile agar masyarakat dapat melihat segala informasi tentang perkembangan pembangunan sebuah desa.

\section{METODE PENELITIAN}

Dalam penelitian ini, peneliti menggunakan metode pengumpulan data seperti observasi, wawancara dan juga studi pustaka. Berikut iniadalah alur penelitian yang digunakan sebagai berikut :

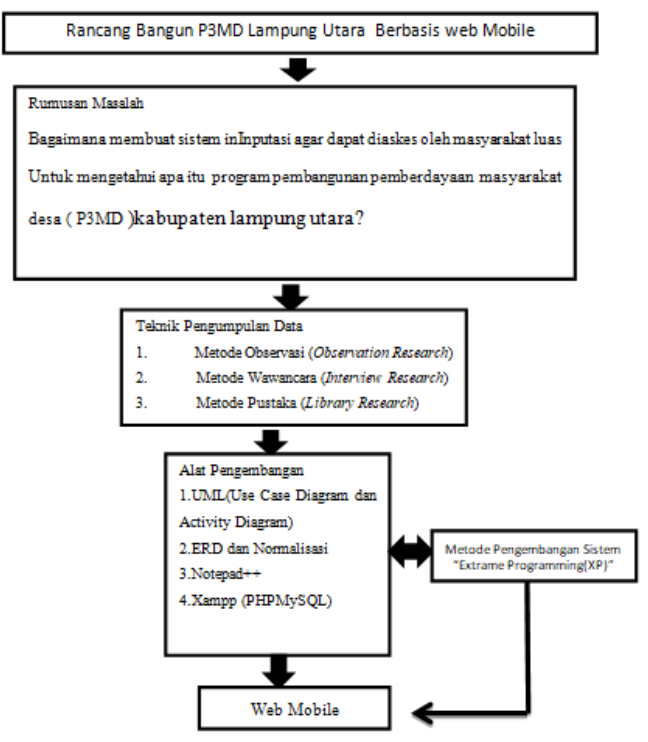

Gambar 1 Alur Penelitian

Disamping itu juga peneliti menggunakan metode pengembangan system extreme programing dalam proses pengembangan web mobile P3MD.

\subsection{Sistem Model Prototyping}

Menurut Jonh Wiley and Son dalam bukunyA System Analisis and Design With UML Vwrsi 2.0,Prototype atau Prototyping merupakan salah satu metode pengembangan perangkat lunak yang banyak digunakan [1]. Dengan metode prototyping ini pengembang dan pelanggan dapat saling berinteraksi selama proses pembuatan sistem. Sering terjadi seorang pelanggan hanya mendefinisikan secara umum apa yang dikehendakinya tanpa menyebutkan secara detail output apa saja yang dibutuhkan, pemprosesan, dan data-data apa saja yang dibutuhkan. Sebaliknya di sisi pengembang kurang memperhatikan efisiensi algoritma, kemampuan sistem operasi, dan interface 
yang menghubungkan manusia dan komputer. Tahapan-tahapan dalam Prototyping adalah sebagai berikut:

\section{a. Planning}

Proses memahami mengapa sistem harus dibangun dan mendefinisikan persyaratan. Ini juga mencakup studi kelayakan dari perspektif yang berbeda, teknis, ekonomi, dan aspek kelayakan organisasi.

b. Analysis

Fase ini meliputi kegiatan seperti mengidentifikasi masalah dan analisis, dan bahkan memprediksi potensi masalah yang mungkin timbul di masa depan mengenai sistem. Kiriman / produk dari fase ini akan mendorong bagaimana sistem akan dibangun dan membimbing karya pengembang.

\section{c. Design}

Desain analisis sistem mengarah ke desain keputusan, yang justru menentukan bagaimana sistem beroperasi dalam hal proses, data, perangkat keras, infrastruktur jaringan, antarmuka pengguna, dan faktorfaktor penting lainnya dalam lingkungan sistem.

\section{d. Implementation}

Fase ini yang paling memakan waktu, sumber daya, biaya. ini adalah ketika sistem sebenarnya dibangun, diuji, dan akhirnya diinstal, juga mencakup kegiatan seperti pelatihan pengguna dan pemeliharaan sistem.

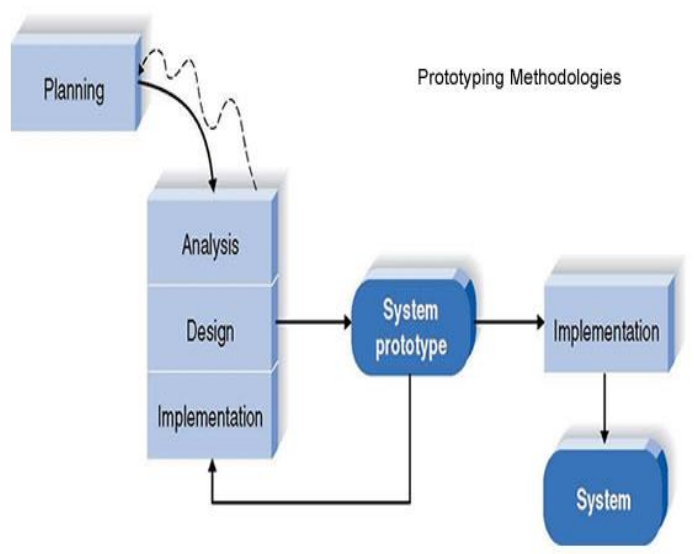

Gambar 2 Prototyping

\subsection{Web Mobile}

Menurut Eko Priyo Utomo, Mobile Web Programming (2013) [2] dalam jurnalnya yang berjudul Aplikasi Delivery Order Berbasis Web Mobile Pada Trotoar Steak mengatakan bahwa "Web Mobile merupakan web atau halaman website internet yang dapat digunakan atau diakses pada perangkat mobile. Skrip yang digunakan untuk mendeteksi bisa menggunakan bahasa PHP dan Java Script”.

\section{HASIL DAN PEMBAHASAN}

\section{3,1 Analisis Sistem}

Analisis sistem merupakan tahapan untuk menemukan kelemahan dan kebutuhan sistem yang bertujuan untuk memperoleh gamabaran sistem yang akan diterapkan melalui identifikasi user terhadap implementasi perangkat lunak. Berikut adalah hasil analisis yang telah dilakukan :

\subsubsection{Usecase Sistem}

Usecase sistem menggambarkan kerangka kerja aplikasi atau sistem yang akan dibuat pada tahapan koding.

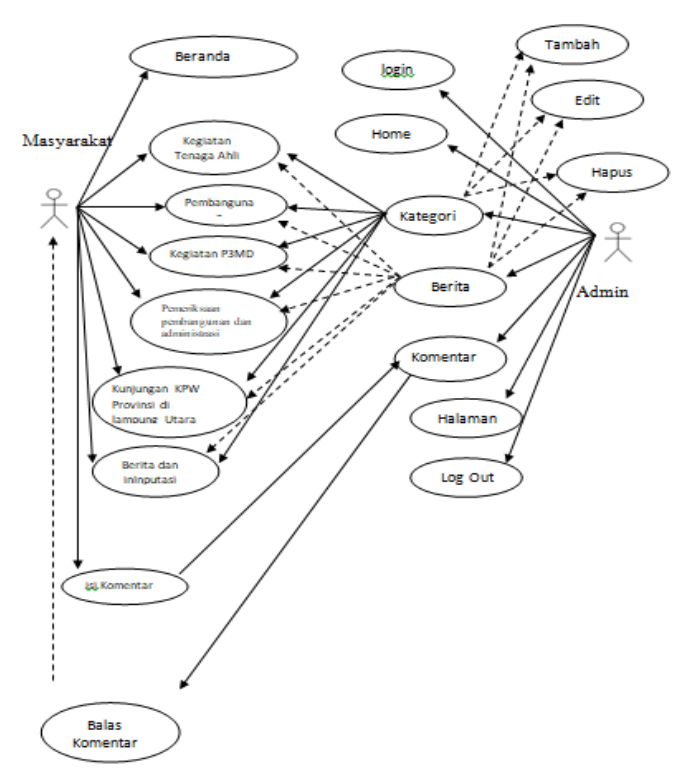

Gambar 3 Analisis Use Case Sistem P3MD

\subsubsection{Diagram Activity}


Diagram activity menggambarkan alur kerja system yang akan dibuat pada tahapan koding.

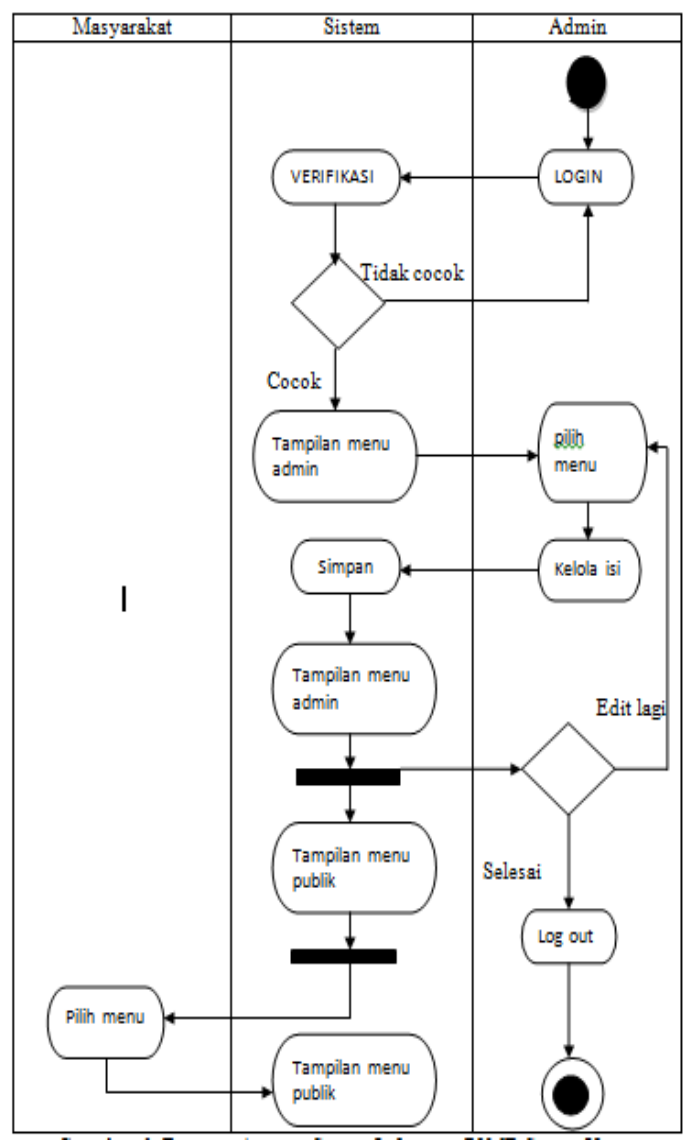

\section{Gambar 4. Diagram Activity Sistem P3MD}

\subsection{Desain Sistem}

Desain system merupakan tahapan berikut nya setelah melakukan tahapan analisis system. Desain system merupakan tahapan pembuatan prototype aplikasi yang akan dibuat. Berikut adalah tahapan dari desain system :

\subsubsection{Class Diagram}

Pada tahapan desain class diagram menggambarkan desain atau kerangka database yang akan di implmentasikan pada tahapang koding.

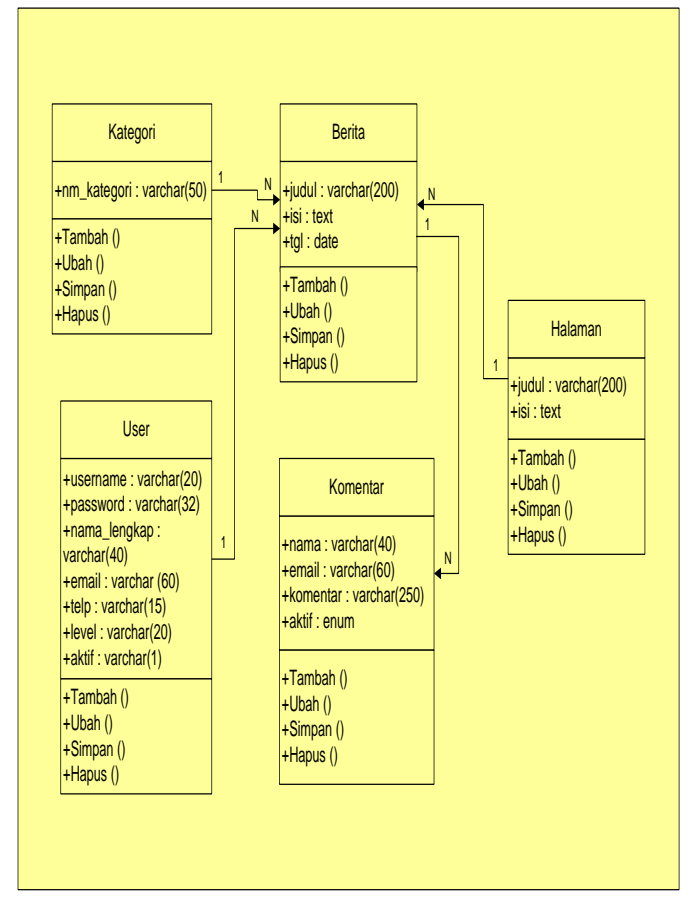

\section{Gambar 4 Class Diagram Sistem P3MD}

\subsubsection{Halaman Admin}

Halaman admin merupakan halaman dashboard utama tempat admin mengupdate segala bentuk data yang akan di publish pada halaman utama.

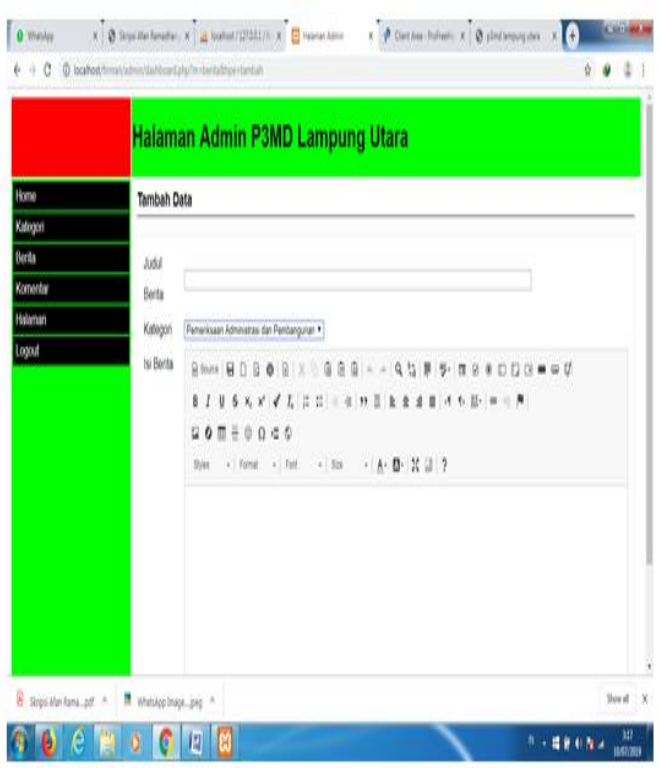

Gambar 5 Halaman Menu Admin

\subsubsection{Halaman Menu Pembangunan}




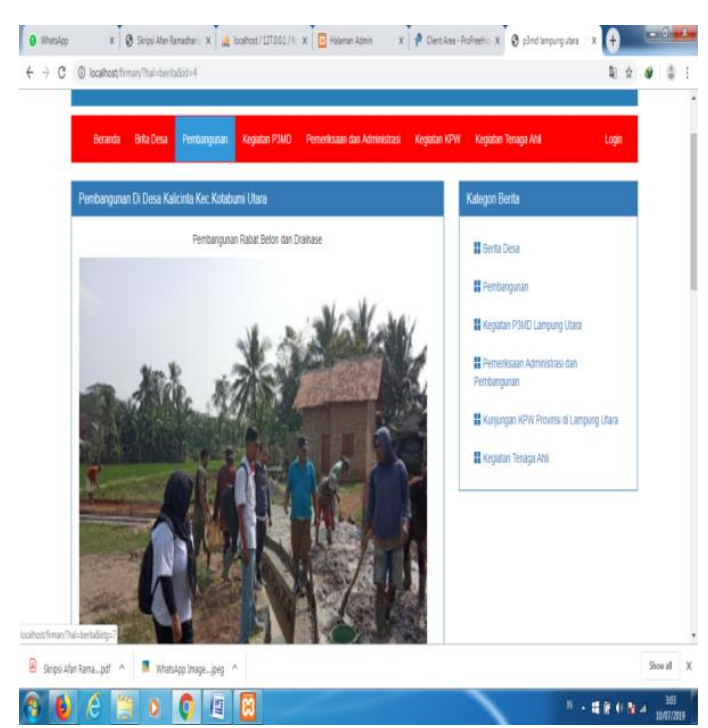

\section{Gambar 6 Menu Kegiatan Desa}

Pada halaman menu pembangunan menggambarkan segala proses kegiatan pembinaan dari P3MD untuk pembangunan desa.

\section{PENUTUP}

\subsection{Kesimpulan}

Setelah melakukan proses penelitian dan disimpulkan bahwa :

1. Proses penyebar luasan informasi yang bersifat Pembangunan maupun non Pembangunan menjadi lebih cepat.

2. Dapat menjaga konsistensi data, dan penyimpanan data menjadi menjadi terstruktur karena menggunakan komputer sebagai alat bantu pemproses data.
3. Keamanan data lebih terjaga, karena hanya Admin web yang terdata yang bisa memanajemen data-data tersebut.

\subsection{SARAN}

Untuk perangkatdesa diharapkan dapat menambah wawasan terkait implementasi teknologi informasi di desa, terutama dalam proses pemahaman terhadap sistem P3MD. Dan juga setiap desa harus memperhatikan akan kebutuhan infrastruktuk perangkat keras guna menunjang sistem P3MD.

\section{DAFTAR PUSTAKA}

[1] Eko Priyo Utomo, Mobile Web Programming dalam jurnalnya yang Berjudul Aplikasi Delivery Order Berbasis Web Mobile Pada Trotoar Steak. (2013)

[2] Jonh Wiley and Son, System Analisis and Design With UML Versi 2.0. (2005)

[3] Menurut Gordon B. Davis, Pengertian Informasi menurut para ahli , Sarjanaku (1991: 28)

[4] Situs resmi kementerian desa : www.kemendesa.go.id sejak2015

[5] Efendi, Dwi Marisa, Muhammad Bayu, and Joni Darsyah. "Sistem Informasi Geografis Lokasi Kos Dan Penginapan Berbasis Web Pada Wilayah Kotabumi Kabupaten Lampung Utara." Jurnal Informasi Dan Komputer 6.2 (2018): 1-10. 